\title{
有机化学专业课中开展课程思政的探索与实践
}

余能芳*，张金兰，任瑞，蒋小妹，曾艳，刘盛华，原弘

华中师范大学化学学院, 武汉 430079

摘要: 在有机化学专业课程中挖掘思政资源进行课程思政的探索与实践, 进而达到传授专业知识并育人的目的。有 机化学中的课程思政资源非常丰富, 融入点也很多, 作者概括为以下四个主要方面, 并探索将其应用于有机化学专 业教学中课程思政工作的途径: 1) 辩证唯物主义的呈现和深化; 2) 爱国情怀的激发和责任担当意识的培养; 3) 科 学素养和创新意识的培养；4) 科学发展与社会生活的结合和渗透。

关键词: 有机化学; 课程思政; 资源; 挖掘; 应用

中图分类号: G64; O6

\section{Exploration and Practice on Course Ideology and Politics in Professional Classes of Organic Chemistry}

Nengfang She *, Jinlan Zhang, Rui Ren, Xiaomei Jiang, Yan Zeng, Shenghua Liu, Hong Yuan

College of Chemistry, Central China Normal University, Wuhan 430079, China.

Abstract: In the courses of organic chemistry, the resources are explored to carry out the exploration and practice of course ideology and politics, so as to achieve the purpose of imparting professional knowledge and educating students. The courses of organic chemistry are very rich in ideological and political resources, and there are many integration points. The authors summarize the following four main aspects and explore the ways of application in the development and practice of ideological and political work in the teaching of organic chemistry: 1) the presentation and deepening of dialectical materialism; 2) the inspiration of patriotic feelings and the cultivation of the sense of responsibility; 3) the cultivation of scientific literacy and innovation consciousness; 4) the combination and penetration of scientific development and social life.

Key Words: Organic chemistry; Course ideology and politics; Resources; Exploration; Application

中共中央国务院颁发的《关于进一步加强和改进大学生思想政治教育的意见》指出, 学校教育 要坚持育人为本、德育为先, 把人才培养作为根本任务, 把思想政治教育摆在首要位置。这里的思 想政治教育不仅仅单纯指学生在课堂上接受的传统的思政课程, 还指教师从不同专业课程中积极发 掘文化基因和价值范式, 与思政课程内容进行恰当的融合, 转化为弘扬社会主义核心价值观的生动 教学载体, 以探索和发展对学生产生影响的教育方式 ${ }^{[1]}$ 。教师要认真传授专业知识, 同时也不忘在 课堂上引导学生坚持正确的政治方向, 坚持正确的价值追求, 进行 “润物细无声” 的理想信念的精 神引领, 这就是课程思政。课程思政是思想政治教育概念的丰富与拓展, 同时也是专业课程教学实 
现内涵式提升与发展的路径选择 ${ }^{[2]}$ 。

目前, 全国范围内已经有许多高校相继开展 “课程思政” 的教学改革。任何专业都有体现自身 特色的思政资源可以挖掘, 但是要发挥课堂主渠道功能, 既要重视具体科学知识的教学, 又要体现 育人目标, 这就需要教师自身具有深厚的专业功底, 同时还要积极主动地在教学内容以及教学方法 等方面进行大胆的探索和创新。

我们在有机化学教学过程中, 也要充分将学科自身的优势特点与思想政治教育有机融合, 最终 达到传播专业知识同时发挥育人功能的目的。那么如何在有机化学这门专业课程中开展和实施课程 思政呢? 教师要主动挖掘体现有机化学自身专业特色的、具有说服力、感染力的思政元素和案例, 比 如有机化学知识背后的历史及文化, 有机化学发展史上的重大事件等, 将显性教育与隐性教育融会 贯通, 潜移默化地树立学生的社会主义核心价值观; 将热点问题引入专业教学中, 激发学生关注社 会、崇尚科学、热爱科学、热爱所学专业的意识, 并肩负起推动科学进步、保护和增进人类健康、 预防和治疗疾病的神圣使命和社会责任。具体可从以下四个方面进行开展和实施。

\section{1 辩证唯物主义在有机化学教学中的呈现和深化}

辩证唯物主义思想在自然科学的教学过程中有着充分的呈现。例如在有机化学的第一章绪论中, 教师在介绍有机化学的发展历史时, 可以将维勒首次人工合成尿素, 打破了有机化合物和无机化合 物的界限, 从而推翻了唯心主义 “生命力学说” 的里程碑事件作为辩证唯物主义呈现和深化的案例, 即实践是检验真理的唯一标准, 还可进一步培养学生辩证唯物主义世界观的形成。另外, 有机化学 作为一门源于实验的学科, 更是处处体现辩证唯物主义的思想。我们日常生活中的衣、食、住、行 各个方面都离不开有机化合物, 它们和其他物质共同构成当今世界。世界是物质的, 物质是不断运 动变化的, 在这个统一的物质世界中包含多种物质形态及结构。在有机化学中的呈现就是有机物的 各种形态以及多种多样的异构现象, 如碳链异构、位置异构、官能团异构等, 教师在传授这些专业 知识时要着重体现物质的存在与变化, 于知识点中渗透辩证唯物主义思想。比如, 烷烃每增减一个 或几个 $\mathrm{CH}_{2}$, 就从一种烷烃变成另一种新的烷烃, 那么它们的性质也相应地会表现出不同, 这些客 观的知识充分体现了物质的量变会引起质变的辩证规律 ${ }^{[3]}$ 。另举一例说明, 在讲解烷烃、烯烃、炔烃 等章节的知识时, 教师可以注重体现知识之间的连续性与区别性, 这样有助于学生发现知识之间的 矛盾, 而这些矛盾又能推动课堂的顺利进行, 能帮助学生对知识产生较为连贯的理解, 正如列宁指 出: “就本来的意义说辩证法就是研究对象的本质自身中的矛盾”, 矛盾存在于客观物质世界和科 学研究的一切领域, 是事物运动和发展的动力 ${ }^{[4]}$ 。在有机化学教学中教师要有计划、有目的地对学 生进行辩证唯物主义的思想教育, 提高学生辩证唯物主义思想水平, 这样不仅能有效地帮助学生更 深刻地理解和掌握有机化学知识, 还能使学生认识到事物发展的过程, 培养学生运用唯物主义科学 世界观解决问题的意识。

\section{2 爱国情怀与责任担当意识在有机化学教学中的激发和培养}

培养爱国情怀有利于激发大学生的爱国主义情感, 帮助学生树立正确的政治观和价值观, 强化 他们的责任担当意识和民族使命感。爱国情怀的激发和责任担当意识的培养不仅有利于学生自身的 健康成长, 还关系到社会的和谐进步, 更关乎民族和国家未来的发展。在有机化学教学过程中可以 介绍当代中国著名的化学家及他们对有机化学做出的重要贡献 ${ }^{[5]}$, 比如: 1965 年, 首次人工合成结 晶牛胰岛素; 1981 年, 首次完成酵母丙氨酸转移核糖核酸的人工全合成; 2015 年, 屠呦呦凭借青蒿 素的研究而获得诺贝尔奖。更早则有中国科学家黄鸣龙冲破种种阻力, 从瑞士携妻带女回到祖国, 还带回一批仪器设备, 投身到新中国的科学事业中, 通过多年忘我的实验研究发现了一个重要的化 学反应——沃尔夫-基斯内尔-黄鸣龙还原反应, 这成为很长时间以来唯一以中国人名字命名的化学 反应。这些重大并产生深远影响的历史事件以及优秀化学家事迹的介绍, 不仅能够提高课堂的趣味 
性, 而且能够激发学生的爱国情怀, 使学生了解到在有机化学的发展进步过程中离不开中国科学家 的无私奉献, 还能培养学生的社会责任感和担当意识, 增强学习的动力, 提高学生的民族自豪感与 文化自信。另外教师还可以帮助学生认识到现在课堂上所学的知识可以发挥巨大的力量, 同时自己 作为祖国未来的接班人也要承担起推动科学进步、保护人类健康的神圣使命和社会责任 ${ }^{[6]}$ 。下面举 例就屠呦呦获诺贝尔奖事件开展课程思政的具体过程: 对于该案例, 教师首先在课前布置相关资料 收集任务——查阅第一个获得诺贝尔生理学或医学奖的中国科学家屠呦呦的人物经历及其科研价 值; 课中请学生以 PPT 形式呈现查阅的资料, 教师给予点评, 进行价值观引领; 课后布置小论文写 一篇你对屠呦呦获诺贝尔奖的感想(500-1000 字)。学生的反馈能反映出此次课程思政的实施效果较 好: “本次课程中对屠呦呦科学家的人物经历和科研经历以及青蒿素知识的学习, 既大大激发了我 们学习有机化学的兴趣和研究有机化学的热情, 又增强了我们的民族自豪感和爱国主义情怀, 此外 也培养了我们将来从事于有机化学研究的志向, 让我们懂得做科学研究需要有实事求是的品质、铸 而不舍的精神, 还要能耐得住寂寞, 经得起考验。”

\section{3 科学素养和创新意识以及创新能力在有机化学教学中的培养}

科学素养又称为科学素质, 通常包含科学情感、科学态度、科学方法及科学思维等。著名化学 家戴安邦说过: 化学教学既要传授化学知识和技术, 更要训练科学方法和思维, 还要培养科学精神 和品德。以第五章对映异构的教学为例, 教师可以介绍联邦德国 50 年代生产的一种毒性低、副作用 小、十分温和的镇静安眠药 “反应停” (沙利度胺), 它是当时治疗孕妇妊娠初期反应的特效药, 能有 效缓解呕吐症状, 但由于妨碍了孕妇对胎儿的血液供应, 导致了成千上万 “海豹胎” 的出现。后经 研究发现, 反应停是由一对对映体构成的混合物, 具有右旋 $(R$ 构型)和左旋 $(S$ 构型)两种结构, 其中右 旋体 $(R$ 构型) 对缓解孕妇妊娠反应有明显作用, 而左旋体 ( $S$ 构型)却具有致畸性。据了解, 当时有关 该药的安全性评估几乎都来自动物实验, 缺少严格的临床实验, 就开始在多个国家投入使用并成为 “孕妇的理想选择”。而该药在向美国食品和药物管理局(FDA)提出上市销售申请时, 因其临床实验 研究数据不全面和其他副作用而遭到 FDA 审查员的极力反对, FDA 审查员要求研究人员对其进行 更深入的临床研究。后续事实证明, “反应停” 的畅销确实造成了上万名新生婴儿畸形的悲剧, 也 正是美国审查员以严谨求实的科学精神和对实验数据的严谨认真将 “反应停” 拦在了美国门外, 守住 自己的职业操守与道德底线, 挽救了美国数以万计的婴儿, 避免悲剧的再次上演。教师以 “反应停” 事件作为融入点, 不仅可以激发学生对手性和手性药物相关概念的学习兴趣, 还可以借此教育学生严 谨对待实验数据, 向学生强调树立严谨治学精神的重要性, 培养学生保持严谨求实的科学态度, 传 递敬畏生命、崇尚真理的科学精神。引导学生在以后的科研过程中, 一定要树立严谨的科学态度, 坚守职业操守与道德底线, 胸怀对国家、对人民负责的态度, 不断地进行深入的系统研究, 因为科学 容不得半点马虎。

另外在有机化学教学中, 为培养学生的创新意识和创新能力, 教师应更新教学模式, 创新教学 理念, 在教学过程中体现 “学生为中心、教师为主导、创新思维为核心” 的教学思想。采用启发式、 探究式及研讨式等教学方法, 通过给出问题式教学材料或创设科学研究情景或提出科学问题, 组织 学生进行猜想和假设, 收集证据并形成观点, 通过交流讨论最终解决问题, 即让学生通过主动探索、 发现和体验, 培养学生的创新意识和创新能力。在有机化学教学中, 对学生进行有机化合物及有机 化学理论发展史的教育, 就是对学生极为生动的创新教育。在适当的章节引入科学家创新的思想火 花及创新创业的案例, 可以教育学生为了创新应当如何努力地进行艰苦的知识积累, 如何培养自己 形成勤于并善于思考的习惯, 如何及时抓住一时闪现的思想火花, 让学生明白只有通过坚持不解的 努力, 才能产生创新之举, 从而达到培养学生创新意识的目的。另外可以紧密结合当今科技前沿并 在有机化学教学中加深有机化学前沿内容的拓展, 进一步启发学生的创新思维。例如, 在第六章卤 代烃的教学中, 如何解决 $\mathrm{S}_{\mathrm{N}} 1$ 反应产物的分布和立体选择性问题, 特别是手性季碳中心的立体选择 
性的调控, 一直是不对称合成(手性合成)化学领域科学家们面临的悬而未决的难题。教师可以引导 学生基于 $\mathrm{S}_{\mathrm{N}}$ 反应的碳正离子机理, 进行大胆设想, 提出自己的设计方案, 师生进行研讨, 分析方 案的可行性, 最后给学生呈现哈佛大学 Jacobsen 教授 ${ }^{[7]}$ 在此方向实现的重大突破(Nature 封面文章), 帮助学生认识到科学研究要勇于思考与探索, 才能不断取得创新, 从而培养学生的创新意识以及勇 于创新、敢于尝试的科学精神。训练学生创新思维的方法则是教给学生查阅文献的方法, 在对科研 工作者基本素质做出深入分析的基础上, 提出提升大学生科研能力的对策。最后怎样来锻炼并提高 学生的创新能力则需要结合有机化学实践训练来进行。教师可以在实验教学中开展大学生创新性实 验, 进行互动式教学, 引导、启发学生的创新个性, 鼓励学生对现有实验方法进行改进。总之教师 要善用有机化学知识, 认真研究并经过不断探索来构建新的有机化学教学体系, 努力从多方面培养 学生的质疑能力、发散思维、想象思维、逆向思维和直觉思维, 充分发挥学生的思维潜能, 培养学 生的创新意识, 增强学生的创新能力, 这样才能培养出具有创造能力和创新思维的新型人才, 以适 应新形势下市场经济对专业人才的需求，更好地服务社会、服务人民 ${ }^{[8]}$ 。

\section{4 科学发展与社会生活在有机化学教学中的结合和渗透}

在人类历史进步中, 有机化学扮演着重要的角色, 它与人类生产生活和社会发展的方方面面都 有联系, 通过它们之间的紧密结合, 教师可以借此激发学生的学习热情, 提高学以致用的能力。以 有机化学与生态环境为例, 习近平总书记曾提出 “绿水青山就是金山银山”, 这说明良好环境对人 类发展的积极作用, 因此我们要充分意识到生态保护的重要性。习近平新时代生态文明思想在有机 化学教材中也有着具体体现, 教材编写中有 “绿色有机合成” 这一章节, 绿色化学又称为环境无害 化学或者清洁化学, 是化学家通过对化学实验的进一步探究与创新, 发展新的技术, 从而避免使用 对环境或者人体有害的化学药品的化学实验方式。从环保角度来看, 绿色化学可以从源头消除污染, 实现零排放 ${ }^{[9]}$ 。教师要在 “绿色有机合成” 章节中重点体现生态文明的重要性, 并且引导学生实际运 用到有机化学实验中。在有机物设计合成的教学过程中, 教师也应从设计路线入手, 在实验原理和 实验过程中渗入绿色化学的基本理念, 引导学生树立绿色化学思想观念, 达到增强环境保护与自我 保护意识的目的。如在设计实验路线时, 尽量避免使用易挥发的、有毒的溶剂, 要充分考虑反应物 的溶解性等其他重要性质, 寻找能够替代该溶剂的、并且性质较为友好的溶剂。对于某些化合物来 说, 苯的溶解性非常好, 所以常常被研究者使用, 但是苯易挥发, 具有致癌的高毒性, 因此我们寻 找能够替代苯的溶剂, 比如苯的同系物甲苯, 其毒性就要小很多。这一举措就体现了在有机化学教 学过程中培养学生生态文明意识的思想, 以促进人类社会科学发展。

另外, 在社会生活中, 有机化学甚至会被不法分子错误利用, 对人类造成难以估量的伤害, 因 此需要加强有机化学在日常生活的正确渗透, 守护社会各方面安全稳定。比如, 有机化学和食品健 康就有着密切的联系, 因此在有机化学教学中渗透食品安全知识, 对学生进行食品安全教育、强化 学生的食品安全意识方面有着得天独厚的条件 ${ }^{[10]}$ 。例如在讲含氮有机化合物章节时, 可以结合新闻 时事, 如 “苏丹红事件” ——肯德基的 “新奥尔良烤翅” 等五种产品中检测出苏丹红而被停售; “红 心鸭蛋” 涉红事件也被曝光, 由此引出偶氮化合物的学习。苏丹红是一类偶氮化合物, 常用作化工 染色剂, 并非食品添加剂, 因其具有致癌性, 对人体的肝、肾等器官具有明显的毒副作用而被禁止 使用于食品中。但不法商家为了提高食品的色泽, 吸引消费者而在食品中添加苏丹红, 由此提醒学 生如果发现鸡蛋、鸭蛋的蛋黄特别红; 鸡翅、鸡柳、辣椒面的颜色过于鲜艳时要引起警觉, 可能含 有苏丹红。再比如 “瘦肉精事件” “地沟油事件” “三聚氧胺事件” 等等, 教师在课堂教学中引入 此类食品安全与有机化学相关的新闻时事, 不仅可以提高学生的学习兴趣、活跃课堂气氛, 还可以 增强学生的食品安全防范意识和食品忧患意识, 引导学生呼呼人们应该正确地把有机化学知识应用 到食品加工企业中, 做到以人为本, 而不是作为牟取利益的手段。始终传递有机化学能让世界更美 
好的思想, 引领学生树立学习有机化学是要造福人类, 而不是祸害他人的正确的价值观。

\section{5 结语}

课程思政打破了传统的依靠思想政治教师 “单兵作战” 进行育人的局面, 让每一位教师在各自 的专业课程领域承担起传播思想意识、弘扬民族文化、对学生进行德育教育的责任。有机化学作为 一门与人类社会生活和环境紧密相关的科学, 在课程思政教学方面虽然有很多的政治资源可以挖掘, 但还是要求教师要充分地发挥主观能动性, 提高自身师德修养, 不仅要有扎实的专业知识基础, 还 要积极学习思想政治方面的内容。在课程内容设计上做到以价值引领为主线, 让学生感受 “有温度 的课堂”; 在课堂上做到适当提取专业知识片段与思想政治元素的有机融合, 对学生进行潜移默化、 春风化雨般的思政教育, 最终达到教书育人的目的, 形成有机化学专业课程与思想政治理论课同向 而行、协同发展的局面。

\section{参 考 文 献}

[1] 吴涛. 电脑知识与技术, 2017, 13 (28), 143.

[2] 田鸿芬, 付洪. 未来与发展, 2018, No. 4, 99.

[3] 黄素珍. 福建教育学院学报, 2003, No. 9, 55.

[4] 列宁. 列宁全集 第 38 卷. 北京: 人民出版社, 1960: 278.

[5] 徐丹, 尹雪娜, 马世坤. 中国高等医学教育, 2018, No. 10, 31 .

[6] 韩国志, 刘睿, 关建宁. 大学化学, 2019, 34 (11), 57.

[7] Jacobsen, E. N.; Wendlandt, A. E.; Vangal, P. Nature 2018, 556, 447.

[8] 张甜, 傅玉琴. 广州化工, 2013, 41 (9), 232.

[9] 袁华, 吴莉, 邓惠文, 杜治平, 尹传奇, 童俊林. 科技创新导报, 2008, No. 16, 210.

[10] 郭今心, 朱荣秀, 赵全芹, 李明霞, 张树永. 大学化学, 2019, 34 (11), 54. 